\title{
Inovasi dan Pembauran Genre dalam Pertunjukan Keroncong Wayang Gendut
}

\author{
Bondet Wrahatnala ${ }^{1}$
}

Program Studi Etnomusikologi, Fakultas Seni Pertunjukan, Institut Seni Indonesia Surakarta

\begin{abstract}
Innovation and Genre-Mixing in the Performance of Wayang Gendut Keroncong. This paper aims to discuss the forms of design and genre-mixing carried out by Wayang Gendut Keroncong Congwayndut Group in Surakarta, which tries to offer a wayang performance with a more interactive packaging. The universal evolution approach uses the analytical tool in this paper to examine the new elements offered by Congwayndut as a form of innovation in the puppet show. The research method used is qualitative with a descriptive model. The conceptual approach and research methods found that the creation and genre-mixing carried out by Congwayndut were implemented in music, stories, and performance form. The use of keroncong music with combos and contemporary bands is the main illustration in the show. They are still based on the epics of Ramayana and Mahabharata but actualized in current phenomena in society. Congwayndut's innovative form of performance is packaged in interactive language and builds closeness to the audience. It is intended to convey the messages and values readily accepted and understood by the audience, whose segmentation is the younger generation.
\end{abstract}

Keywords: Congwayndut; keroncong music; the story of the show; performance form

\begin{abstract}
ABSTRAK
Tulisan ini bertujuan untuk mendiskusikan bentuk inovasi dan pembauran genre yang dilakukan oleh kelompok Keroncong Wayang Gendut -Congwayndut -di Surakarta, yang mencoba menawarkan bentuk pertunjukan wayang dengan kemasan yang lebih interaktif. Pendekatan evolusi universal digunakan sebagai alat analisis dalam penulisan ini, dalam mengkaji unsur-unsur baru yang ditawarkan oleh Congwayndut sebagai bentuk inovasi dalam pertunjukan wayang kulit. Metode penelitian yang digunakan adalah kualitatif dengan model deskriptif. Melalui pendekatan konsep dan metode penelitian yang dilakukan, diperoleh hasil bahwa inovasi dan pembauran genre yang dilakukan oleh Congwayndut diimplementasikan dalam aspek musik, cerita, dan bentuk pertunjukan. Penggunaan keroncong dengan garap combo band dan kontemporer menjadi ilustrasi utama dalam pertunjukannya. Unsur cerita tetap berbasis pada epos Ramayana dan Mahabarata, namun diaktualisasikan dalam fenomena terkini di masyarakat. Inovasi bentuk pertunjukan yang dilakukan Congwayndut dikemas dengan bahasa yang interaktif dan membangun kedekatan dengan penonton. Hal ini dimaksudkan agar pesan dan nilai yang ingin disampaikan akan mudah diterima dan dipahami oleh penonton, yang segmentasinya adalah generasi muda.
\end{abstract}

Kata kunci: ide; Congwayndut; musik keroncong; ceritera; bentuk pertunjukan

\section{Pendahuluan}

Seni pertunjukan dewasa ini mulai berbenah baik dari sisi kemasan hingga terobosan penciptaan seni. Hal ini disebabkan maraknya era digital yang menuntut perubahan secara dinamis untuk semua bidang kehidupan. Seni tradisi salah satu wilayah yang kini gencar melakukan terobosan artistik untuk dapat bersaing searus dengan kondisi global. Oleh sebab itu, banyak bermunculan gejala seni pertunjukan yang proses dan wujud kreatifnya melampaui batas, artinya keluar dari

1 Alamat korespondensi: Program Studi Etnomusikologi, Fakultas Seni Pertunjukan Institut Seni Indonesia Surakarta, Jalan Ki Hajar Dewantara No.19, Surakarta. E-mail: bondet@isi-ska.ac.id; HP.: 081329022596. 
zona mainstream (Wrahatnala, 2020, 116). Salah satunya adalah kelompok seni Keroncong Wayang Gendut -Congwayndut, yaitu kelompok wayang inovatif asal Surakarta, yang mampu menafsir seni tradisi secara kekinian, yang disertai dengan terobosan pembauran berbagai macam ekspresi seni yang interaktif, komunikatif dan merakyat.

Bentuk terobosan yang dilakukan Congwayndut adalah mereka mampu merefleksikan kesenian wayang dengan cara yang baru. Bentuk kebaruan tersebut, masih mengacu pada rule penciptaan pertunjukan wayang tradisi. Hanya saja, konsep penciptaan pertunjukan tersebut disikapi secara lebih modern oleh Congwayndut. Hal ini tampak pada penggunaan keroncong modern sebagai ilustrasi musik untuk pertunjukan wayangnya dengan garap musik yang berbeda dan cenderung mengakomodiasi genre musik dunia lain seperti klasik, pop, rock, hip-hop, dan dangdut. Ditambah dengan penonjolan garap humor yang interaktif dengan penonton. Kemasan pertunjukan yang bersifat humor interaktif ini, justru menyajikan dialog antara penonton dengan dalang dan para pemain musiknya. Bentuk refleksi lain yang dilakukan oleh Congwayndut, muncul pada aspek sanggit cerita, kemasan pertunjukan, kostum para pelaku, dan sajian ceritera atau lakon yang lebih mengedepankan aspek sosial yang sedang menjadi trend di tengah masyarakat.

Bentuk inovasi sebagaimana disampaikan oleh Schumpeter, merupakan upaya untuk mengkreasikan dan mengimplementasikan sesuatu menjadi kombinasi baru, yang dapat menambah nilai produk atau karya baru yang dihasilkan (Mudra et al., 2020, 58). Terminologi inovasi, sangat terkait dengan perubahan. Bentuk perubahan dilakukan sesuai dengan proses kreatif para seniman dan/atau pelaku seni sehingga dapat menghasilkan produk seni baru yang memiliki nilai estetika yang berbeda (Rachmawati \& Prihatini, 2019, 316).

Inovasi merupakan suatu upaya konkret yang perlu dilakukan oleh kelompok kesenian atau para pelaku seni, dengan tujuan pengembangan kesenian itu sendiri. Sebagaimana dituturkan oleh Irianto bahwa perubahan dan berbagai inovasi seni tradisional dengan memanfaatkan teknologi pengembangan dapat dilakukan untuk menjaga dan melestarikan kesenian tradisional (Ridwan et al. 2020: 215). Inovasi yang dilakukan oleh kelompok ini, menunjukkan adanya penekanan pada peristiwa ekspresi pertunjukan melalui pembauran antar berbagai elemen yang terlibat di dalamnya. Baik elemen artistik pertunjukan, maupun elemen pendukung pertunjukan seperti penonton. Karena itulah, menjadi penting untuk memfokuskan penulisan ini pada kemampuan Congwayndut dalam melakukan inovasi yang dilandasi dengan konsep pembauran genre dan dikemas melalui pertunjukan yang interaktif. Karena pada dasarnya, seni pertunjukan secara umum, tidak hanya menghadirkan wujud visualnya saja, namun juga dapat memberikan value kepada penonton dan penikmatnya (Hadi dalam Saaduddin \& Novalinda, 2017, 42).

Inovasi merupakan sebuah strategi yang sengaja berangkat dari tradisi untuk memutakhirkan budaya tertentu agar lebih fungsional bagi masyarakat pendukungnya. Inovasi melibatkan pengembangan solusi untuk persoalan-persoalan artistik. Konsep inovasi yang berkaitan dengan kreasi umumnya merupakan alat baru, produk, metode atau proses yang menginformasikan perspektif baru (Sudirga 2020: 43). Inovasi yang dilakukan oleh Congwayndut ini lebih pada pemecahan persoalan artistik yang terkait dengan ajakan untuk kawula muda agar mempertebal pemahaman terhadap seni pertunjukan dan secara lebih luas mengenai persoalan kebudayaan yang sudah hampir ditinggalkan. Hasilnya, yakni sebuah produk atau proses yang menginformasikan perspektif baru dalam seni pedalangan.

Proses pemindahan berbagai sumber gagasan dan inspirasi ke dalam sebuah bentuk karya seni pertunjukan merupakan sebuah proses yang cukup kompleks, artinya ada berbagai medium di dalam seni pertunjukan sendiri harus dipertimbangkan dan berikutnya dihunakan dalam proses tersebut, yang pada dasarnya membutuhkan kreativitas yang tinggi, untuk menghasilkan bentuk karya seni pertunjukan yang komunikatif dengan penontonnya (Yuliza, 2020, 83). Seni pedalangan sebagai salah satu elemen dalam seni pertunjukan mempunyai bahan baku yang berupa soft material sebagai bahan dasar (medium) untuk digarap, yakni 
bahasa, suara, gerak, dan rupa. Keempat medium ini dapat diolah ke dalam unsur-unsur pakeliran yang meliputi (1) catur, (2) sabet, dan (3) karawitan pedalangan. Antara unsur yang satu dengan lainnya mempunyai fungsi yang berkait dan saling mendukung, baik secara teknis maupun estetis dalam satu kesatuan bentuk sajian suatu lakon pedalangan (Sumanto, Suyanto dalam Harpawati et al., 2015: 153-154). Pembauran yang dilakukan dalam Congwayndut berupaya untuk mempertegas unsur-unsur pakeliran ini dalam kemasan yang kreatif dan komunikatif, dengan tujuan dapat diserap dan diterima dengan baik oleh semua kalangan penonton. Karena faktanya, pertunjukan wayang secara umum selalu kalah bersaing dengan bentuk seni pertunjukan lain yang menampilkan unsur-unsur estetik yang mudah ditangkap oleh para penonton dan penikmat dalam masyarakat (Marajaya \& Hendro, 2021: 64)

Salah satu unsur dalam kemasan kreatif dari Congwayndut adalah memasukkan elemen musikal keroncong di dalam sajian pertunjukannya. Melalui keroncong inilah, pada akhirnya memunculkan karakter pertunjukan wayang yang dikemas oleh Congwayndut ini. Karakter musikal merupakan fenomena musikal yang terelasi dari sebuah permainan melodi, ritme, dan dinamika yang tergarap, terstruktur, dan terpola dengan kiat, model, dan gaya tertentu, sehingga menghasilkan rasa tertentu (Ardana dalam Sukistono, 2014: 185). Kreativitas dalam musikalitas pada penciptaan musik kreasi baru atau kreativitas penciptaan kemasan musik untuk pertunjukan apapun, dapat ditelusuri melalui pembongkaran-pembongkaran pada konsep struktur, melodi, ritme, dinamika, dan harmoni yang memiliki implikasi pada perubahan ekspresi musikal (Sugiartha dalam Prakasih et al., 2018: 114). Kemasan musikal keroncong, yang dilakukan oleh Congwayndut ini, merupakan bentuk inovasi yang dianggap baru dalam dunia seni pedalangan.

Inovasi secara umum merupakan suatu bentuk aktivitas atau kegiatan pembaharuan, namun dalam dunia kreativitas seni inovasi mengandung pengertian sebagai sebuah proses yang terdiri atas tahapan-tahapan tertentu, yang dilakukan oleh individu atau kelompok untuk menghasilkan variasi baru (novelty) dalam suatu kebudayaan (Czikszentmihali, 1999: 315; Kiswanto et al., 2019, 4) . Hasil inovasi Congwayndut merupakan model seni pertunjukan yang mengakomodir beberapa macam konvensi genre, gaya yang terdapat pada bidang seni yang lain, seperti musik, wayang, teater, naskah, rupa, dan dramuturgi. Model ini tidak hanya mengakomodir pengembangan bentuk seni tradisi dalam satu jenis saja, melainkan juga mengakomodir berbagai macam inovasi pada bentuk-bentuk seni yang berada di luar pakem pertunjukan wayang kulit. Congwayndut menjadi wadah sekaligus model yang membaurkan perbedaan-perbedaan elemen artistik dengan keberagaman selera penonton dari berbagai kalangan. Termasuk bahwa Congwayndut diharapkan menjadi gridder seni pertunjukan wayang kulit bagi generasi muda. Dengan adanya Congwayndut ini, generasi muda sebagai audiens pertunjukannya dapat mempelajari lebih jauh wayang kulit purwa dan seni musik keroncong yang dewasa ini, kurang mendapatkan perhatian dari kalangan milenial. Artinya, keberadaan Congwayndut dapat menjadi pintu pertama untuk mengedukasi kawula muda khususnya generasi milenial, agar tetap dapat menerima value yang disampaikan melalui seni pertunjukan.

\section{Metode Penelitian}

Penulisan ini dikaji dengan pendekatan evolusi yang memiliki penekanan pada teori evolusi universal. Peter White sebenarnya mengakui bahwa ada kelemahan besar dalam teori evolusi, namun tidak menolak ide dasarnya dan mengusulkan sebuah kriteria baru, yaitu energi. Karena pada dasarnya setiap kebudayaan pada dasarnya adalah sebuah sistem termodinamis, yakni sistem yang melakukan transformasi energi. Artinya evolusi kebudayaan merupakan perubahan sebuah sistem yang melakukan transformasi energi dengan bantuan teknologi (White dalam Wrahatnala, 2018: 45). Bahwa inovasi dalam bentuk pembauran genre yang dilakukan oleh kelompok wayang Congwayndut di Surakarta ini, merupakan proses transformasi energi dengan bantuan teknologi. Artinya transformasi nilai-nilai yang terdapat dalam pewayangan dikemas dengan menggunakan model pembauran teknologi per- 
tunjukan. Teknologi pertunjukan yang dimaksud adalah pengembangan media dan juga elemenelemen pertunjukan yang dikemas dalam sebuah pertunjukan wayang. Pengembangan dengan bentuk pembauran ini dilakukan oleh Congwayndut sebagai sebuah proses adaptasi terhadap perkembangan lingkungan dan teknologi yang ada dalam kehidupan masyarakat. Di samping itu, pembaharuan seni yang dilakukan oleh Congwayndut, mampu menempatkan posisi sebagai agen perubahan sosial, yang mampu mengelaborasi faktor estetik dan mengelola dorongan-dorongan yang berupa faktor non seni (Mulyani \& Rosilawati, 2020, 71). Oleh karena itu, perlu adanya perilaku inovatif untuk tetap menyuguhkan hasil kebudayaan yang berupa pertunjukan seni wayang kepada generasi baru yang memiliki perspektif lain dalam melihat sebuah pertunjukan. Model pendekatan penelitiannya adalah deskriptif analitik, yakni menggambarkan inovasi yang dilakukan oleh Congwayndut dalam mengemas pertunjukan wayang kulit dengan melalui pembauran genre. Analisis dilakukan terhadap bentuk pembauran genre, baik di wilayah musikal maupun non musikal serta pengaruhnya terhadap audiens.

\section{Hasil dan Pembahasan}

\section{Ikhwal Congwayndut dan Keberadaannya}

Congwayndut terbentuk pada 25 Agustus 2010, diprakarsai oleh Dwi Suryanto ${ }^{2}$, seniman yang berlatar belakang seni pedalangan di Surakarta. Dwi Suryanto merupakan pendiri sekaligus dalang dalam kelompok Congwayndut. Dalam kelompok tersebut, Gendut -demikian sapaan akrabnya, dibantu oleh Aji Agustian, Muhammad Subhan, Oky Prasetyo, Eko Apriyanto, dan Nurseto Bayu Aji ${ }^{3}$, sebagai penata musik sekaligus musisi. Di samping itu diperkuat kehadiran Yeni Arama,
Ameliya dan Luna Kharisma ${ }^{4}$ sebagai vokalis. Pada awal berdirinya kelompok ini, Congwayndut didampingi oleh seorang Danis Sugiyanto, seorang seniman keroncong di Surakarta sekaligus menjadi dosen di Jurusan Karawitan, Fakultas Seni Pertunjukan, Institut Seni Indonesia Surakarta. Secara kompositoris, latar belakang musikal yang digunakan dalam pertunjukan Congwayndut adalah musik keroncong. Genre keroncong dipilih karena menjadi pembeda pertunjukan wayang kulit yang lain. Meskipun keroncong menjadi pilar musikal dalam pertunjukan Congwayndut, namun pengembangan gaya musik kontemporer dan combo band dapat menjadi salah satu upaya eksperimental dalang dan penata musiknya. Musik keroncong menjadi pilihan, karena kenyataan menunjukkan bahwa keberadaan dan kelangsungan musik keroncong merupakan salah satu bentuk seni musik yang hidup, tumbuh, serta berkembang di bumi nusantara dan secara lebih khusus di Jawa adalah pusat perkembangan musik keroncong yang utama dalam sejak abad ke-20 (Christy et al., 2019, 7).

Kehadiran Congwayndut yang diklaim sebagai wayang inovasi mampu memberikan efek yang cukup luas terhadap generasi muda saat ini. Bentuk inovasi ini merupakan bentuk kegelisahan Gendut yang melihat keadaan dunia pewayangan yang menurutnya tidak lagi dapat menyedot minat generasi muda. Di sisi lain, seni pewayangan diharapkan menjadi media pewarisan budaya, namun dalam kehidupan budaya urban ini, seni pewayangan semakin terpinggirkan. Kegelisahan itulah yang kemudian menghadirkan gagasan melahirkan pertunjukan wayang dengan musik keroncong yang dibaurkan dengan genre musik lain seperti musik kontemporer dan combo band. Di samping pembauran genre dalam musik, Gendut dan Congwayndut juga mengetengahkan konsep dagelan dalam pertunjukan wayangnya. Upaya tersebut dimaksudkan sebagai sarana

2 Dwi Suryanto biasa dipanggil Gendut, adalah alumni S-1 Seni Pedalangan Fakultas Seni Pertunjukan ISI Surakarta dan S-2 Penciptaan Teater, pada Program Pascasarjana ISI Surakarta.

3 Aji Agustian, Muhammad Subhan, Oky Prasetyo, Eko Apriyanto, Nurseto Bayu Aji merupakan alumni Prodi S-1 Etnomusikologi, Fakultas Seni Pertunjukan ISI Surakarta, yang berlatar belakang musik barat.

4 Yeni Arama merupakan alumni Prodi S-1 Seni Karawitan dan S-2 Penciptaan Musik di ISI Surakarta, Ameliya merupakan alumni Prodi S-1 Etnomusikologi, sedangkan Luna Kharisma juga merupakan alumni Prodi S-1 Teater dan S-2 Penciptaan Teater di ISI Surakarta. 
untuk mendekatkan diri kepada penonton. Dan untuk menunjukkan bahwa dalam menyampaikan nilai yang ada dalam seni pedalangan, tidak hanya memerlukan suasana yang serius, namun dengan cara santai, membaur, dan tetap santun, serta dikemas secara interaktif. Pemadatan waktu menggelar pakeliran dan penggunaan kelir kecil dari ukuran biasanya, juga menjadi gagasan dan konsep pergelaran Congwayndut.

Dalam kiprahnya, kelompok Congwayndut pada kurun waktu 2011-2019 telah menghasilkan beberapa karya musik dan wayang. Karya musik yang telah dihasilkan di antaranya Musik Tari "Ramayana Kontemporer" 2011, Musik Tari "Macan Ganjur" 2013, Musik untuk Opening Solo International Performing Arts 2013, Musik Gamelan Akbar 2015, dan Festival Keroncong Surakarta 2016. Untuk karya wayang, setidaknya dalam rentang waktu 2010 sampai 2017 telah menciptakan karya pertunjukan wayang yakni "Anoman SMS" 2010, "Wisanggeni Wae Piye?" 2011, "Alap-Alapan Jenakawati" 2011, "Ajaran Sutasoma" 2013, "Partadewa" 2014, "Pahlawan Tanpa Tanda Jasa" 2015, "Dalang Keblegan Kelir" 2015, "Cintaku di Negerimu" 2016, "Digege Mangsa" 2016, "Selo Adha" 2016, dan "Anoman Si Kethek Putih" 2016 (Romadona, 2019a:13). Di samping karya-karya yang telah dihasilkan tersebut, Congwayndut juga terlibat dalam berbagai event seperti Malam Inagurasi Putra-Putri Solo 2016, Malam Penutupan Solo Great Sale 2017, Peraih Hibah Kelola Seni Inovasi pada tahun 2017, Maha Karya Borobudur 2018, dan konser tour yang dilaksanakan di lima kota yakni Madiun, Yogyakarta, Magelang, Purwokerto, dan Surakarta, yang disponsori oleh Produk Minuman Kesehatan Intrafood (Romadona, 2019b: 13).

\section{Pembauran Genre dalam Pertunjukan Congway- ndut}

Sebagaimana telah disinggung pada pembahasan di awal, bahwa kelompok Congwayndut menggunakan konsep pembauran genre dalam pertunjukannya. Pembauran genre yang dimaksud adalah berupaya untuk mengelaborasi aliranaliran di luar konteks tradisional Jawa yang selalu lekat dalam pertunjukan wayang kulit sebagaimana umumnya, untuk dikemas dalam satu wadah pertunjukan Congwayndut. Penjelasan mengenai konsep pembauran ini merujuk pada konsep yang dikemukakan oleh Peter White mengenai evolusi universal. Dalam pandangan tersebut, mengindikasikan adanya unsur-unsur energi baru dalam menggerakkan sistem termodinamika dalam hal ini adalah pertunjukan wayang. Unsur-unsur energi baru dalam penulisan ini diarahkan pada pembauran genre "baru" yang tidak biasa disajikan dalam pertunjukan wayang kulit pada umumnya. Karena justru dengan kehadiran energi baru ini dimaksudkan untuk memperkuat sesuatu yang telah ada, untuk menjadi lebih baik dan fungsional dalam masyarakat.

Pembauran genre atau energi "baru" ini, dalam pertunjukan Congwayndut dapat dikategorikan dalam: (1) Musik; (2) Ceritera; dan (3) Pertunjukan. Dalam tiga kategori tersebut, terdapat pembauran genre yang akan dijelaskan secara deskriptif analitik dalam paparan berikut ini.

\section{Musik}

Musik dapat mengekspresikan perasaan, kesadaran, dan bahkan pandangan hidup seseorang, sehingga musik yang berdampingan dengan seni pertunjukan wayang digunakan untuk mempertegas sebuah adegan. Posisi ini menegaskan peran musik, tidak hanya sebagai pendukung, namun tetap berdiri sebagai media ekspresi (Salim, 2020, 161). Inovasi yang terkait dengan musik merupakan ide atau pengenalan hal-hal baru serta pengembangan ide-ide kreatif melalui unsur musik maupun pembawaannya untuk menghasilkan sebuah aransemen, penemuan atau genre musik baru yang berbeda dengan sebelumnya (A'yun \& Rachman, 2019, 36).

Pada aspek musik, Congwayndut melakukan pembauran tiga wilayah genre musik yakni keroncong, kontemporer, dan combo band. Musik keroncong merupakan pilar ilustrasi dalam pertunjukan Congwayndut, dibaurkan dengan aliran musik lainnya. Jalur garapan keroncong secara lebih khusus yang ada dalam pertunjukan wayang ini adalah keroncong klasik dan keroncong kreasi. Ke- 
roncong klasik yang dimaksudkan adalah garapan musik yang menyajikan lagu-lagu keroncong yang sudah ada seperti langgam keroncong, stambul dan sebagainya, sedangkan keroncong kreasi adalah penyajian musik keroncong dengan menggunakan instrumen musik yang biasa dimainkan dalam combo band dan beat aliran musik yang lain seperti blues, jazz, swing, dan rock (Romadona, 2019b: 15). Tujuan melakukan garapan keroncong "baru" ini jelas untuk membuat suasana pertunjukan Congwayndut menjadi lebih ringan dan nyaman untuk didengarkan dan ditonton.

Genre musik lainnya adalah kontemporer. Sebelum membahas mengenai musiknya, istilah kontemporeryang dimaksudkan dalam penulisan ini adalah gaya musik kekinian dengan menggunakan pendekatan gaya musik barat. Wilayah kebaruan yang digarap adalah unsur musik keroncong, tembang Jawa, dan musik barat itu sendiri. Garapan inilah yang menjadi pembeda pertunjukan wayang ala Congwayndut dengan garapan pertunjukan wayang pada umumnya. Titik garap kompositoris dalam pertunjukan wayang Congwayndut tampak pada sajian musik transisi dan musik ilustrasi, yang disajikan dengan penonjolan pada permainan sukat dan dinamika musik. Permainan yang dinamis ini pun pada akhirnya mempengaruhi gerakan dan gesture wayang yang dimainkan oleh dalang. Intinya, gerakan wayang akan mengikuti ilustrasi musik yang disajikan, karena itu justru ini menjadi wilayah terobosan yang inovatif, dan membuat pertunjukan wayang bisa lebih efektif untuk disajikan kepada penonton.

Konsep genre lainnya adalah format combo band yang juga digarap dengan pendekatan gaya musik barat. Format combo band yang terdiri atas gitar elektrik, bass elektrik, taganing -sebagai pengganti drum set, dan saxophone. Garap musik yang disajikan adalah lagu-lagu populer yang bergenre rock atau pop. Secara kompositoris digabungkan dengan elemen musik keroncong.

Pembauran konsep genre dalam wilayah musik ini menghasilkan musik keroncong kontemporer yang dikemas dalam format combo band. Itu artinya, bahwa musik keroncong yang digarap dengan format combo band ini secara konseptual memang diarahkan kepada generasi muda. Format musik ini dihadirkan untuk stimulus generasi muda agar mereka tertarik untuk kembali menonton wayang, meskipun dengan gaya yang baru. Dengan kata lain, dengan gaya alternatif ini mampu menyedot minat generasi muda untuk dapat menyerap nilainilai yang ada dalam pewayangan yang relevan dengan kehidupan anak muda di zaman sekarang.

Elemen musik yang dihadirkan dalam pertunjukan Congwayndut ditampilkan sebagai penguat karakter suasana dan terlebih pada elemen yang dapat membangun suasana sebuah adegan, sebagaimana perlakuan musik sebagai ilustrasi dalam pertunjukan teater. Karakter musikal yang dibangun melalui pembauran genre yang dilakukan dalam pertunjukan Congwayndut secara berurutan terdiri atas, musik pembuka, ilustrasi adegan, peralihan adegan, efek bunyi, dan musik penutup. Musik yang dikemas ini sama sekali tidak terikat oleh sistem pathet sebagaimana disajikan pada pertunjukan wayang kulit sebagaimana biasanya.

Berikut ini disajikan bentuk garap musik "Talu”. Sebagaimana umumnya dalam pergelaran wayang kulit gendhing Talu disajikan sebelum pertunjukan inti digelar. Dalam pergelaran Congwayndut pun demikian. Gendhing Talu juga disajikan sebelum masuk pada pergelaran intinya. Garap gendhing ini disajikan dengan diawali buka celuk vokal, kemudian disambut dengan alunan keroncong. Pada empat kalimat lagu awal, alunan keroncong mewarnai konstruksi musikalnya, disusul di bagian selanjutnya dengan irama cepat dengan beat instrumen perkusi dengan irama musik rock. Musik "Talu" ini termasuk pada wilayah musik pembuka dalam pertunjukan Congwayndut.

Talu disajikan dengan menggunakan dua irama yakni irama musik keroncong dan musik rock. Karakter yang ingin disampaikan dalam garap musik Talu ini adalah sigrak, rame, dan energik. Garap musik ini, menandai pertunjukan ceritera yang disajikan Congwayndut dimulai. Pada akhir garapan musik ini dibuat anti klimaks, ending dibuat berhenti secara mendadak, dan memancing reaksi penonton. Setelah itu dalang menyampaikan salam dan sapaan kepada penonton, dan dilanjutkan dengan adegan buka kayon.

Garapan musik dalam pertunjukan Congwayndut lainnya adalah pada wilayah musik per- 
alihan, sebagai musik ilustrasi dalam pergelaran ini. Penempatan musik peralihan ini, juga sangat bergantung pada keinginan dalang, yang disesuaikan dengan dinamika adegan dalam pertunjukan ini. Berikut ini disajikan salah satu contoh musik peralihan yakni Srepeg Sar Kliwon. Srepeg Sar Kliwon merupakan salah satu musik yang digunakan untuk kepentingan peralihan dari adegan yang satu ke adegan berikutnya. Bentuk musiknya adalah instrumental yang diawali dengan melodi gitar dengan ritme keroncong kreasi dengan birama 4/4 dan bertangga nada mayor. Kendali musik dipegang oleh melodi gitar, yang dibayangi oleh saxophone dan aksen ritmisnya dikuatkan oleh perkusi dan electric bass. Instrumen cak dan cuk berdiri sebagai pengatur tempo mengikuti alur musik yang dibangun.

Talu Congwayndut

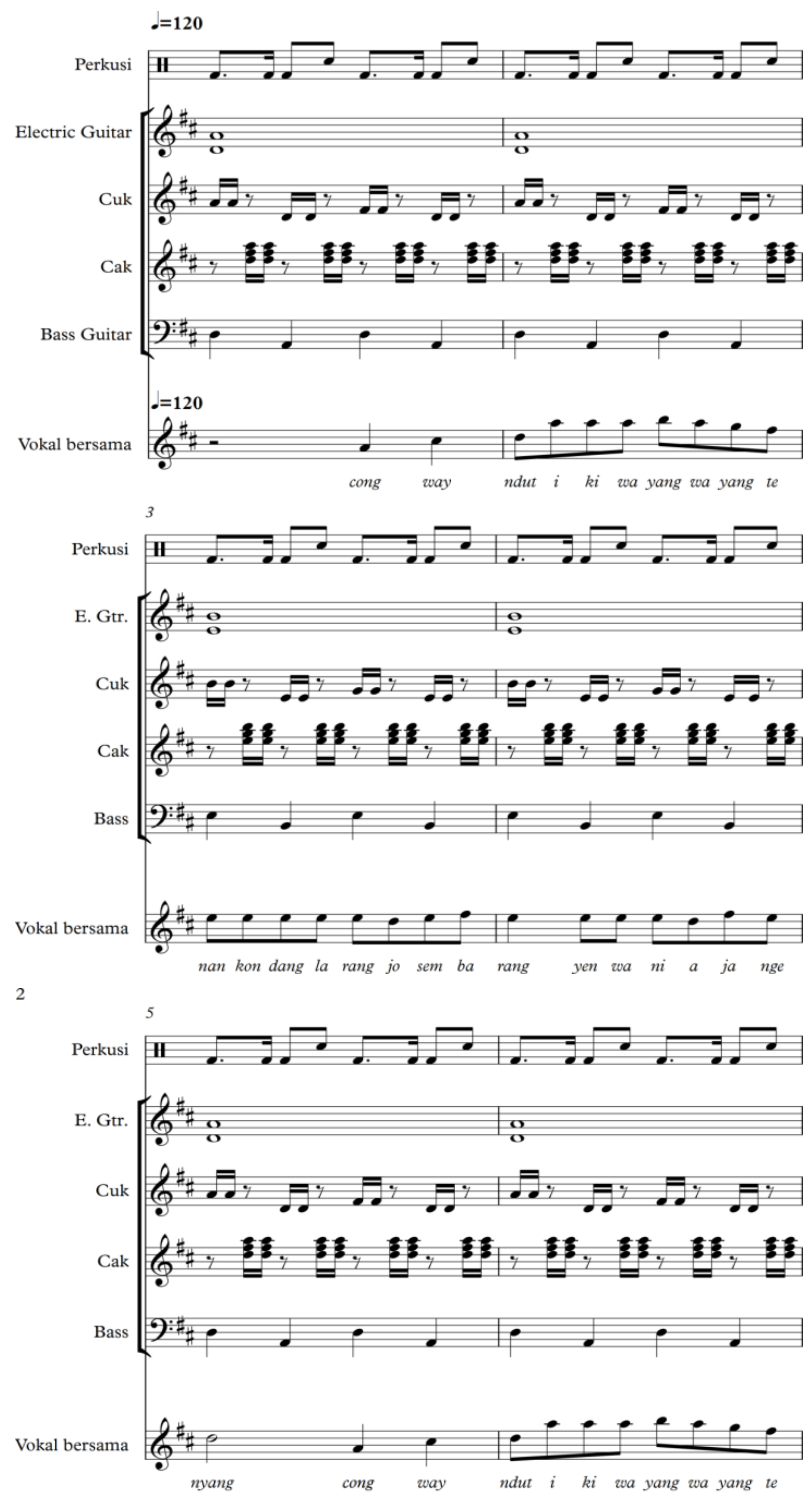

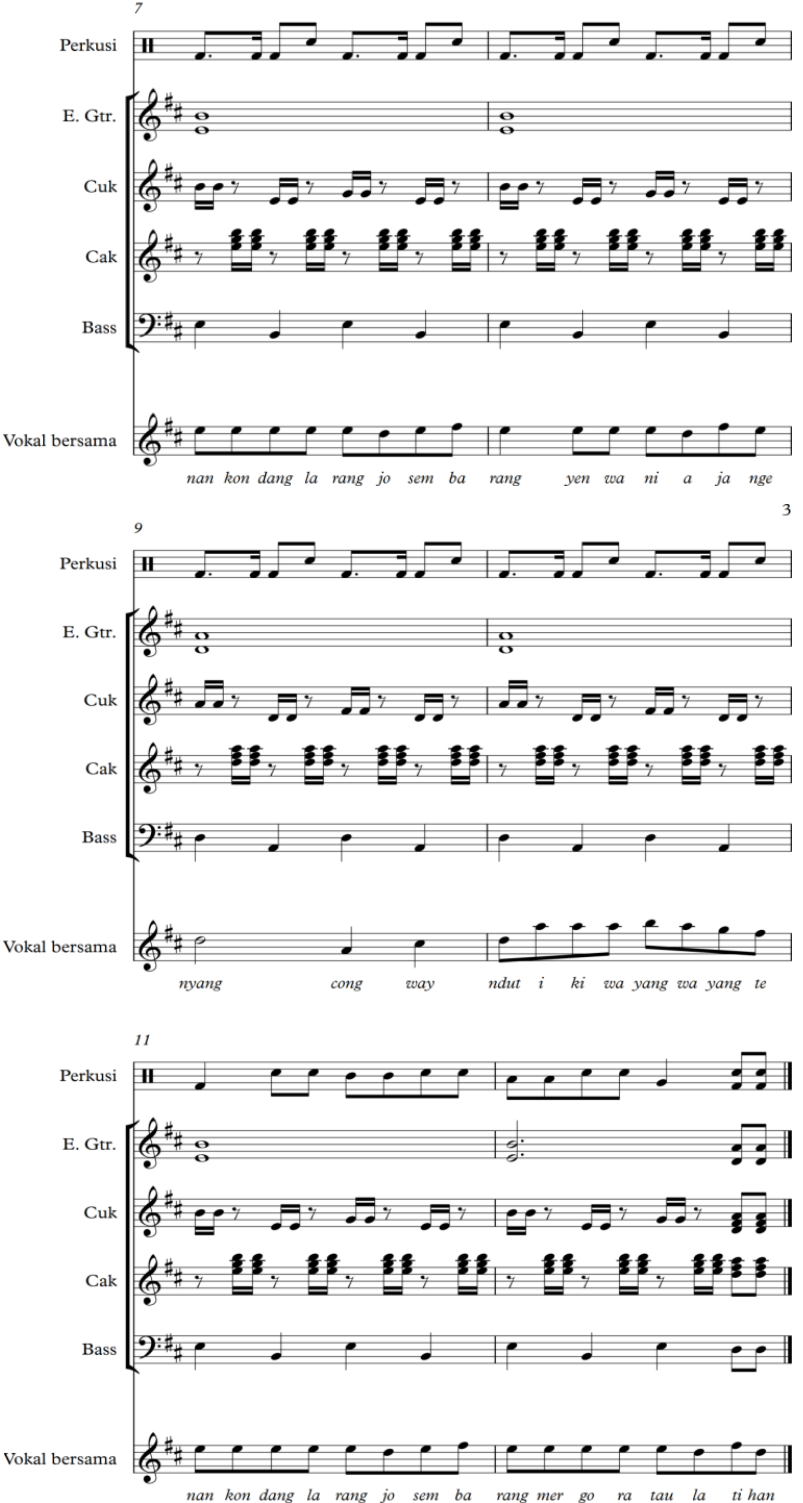

Notasi 1: Musik Talu karya Congwayndut. (Transkrip notasi: Aji Agustian dan Eko Aprianto)

Srepeg Sar Kliwon
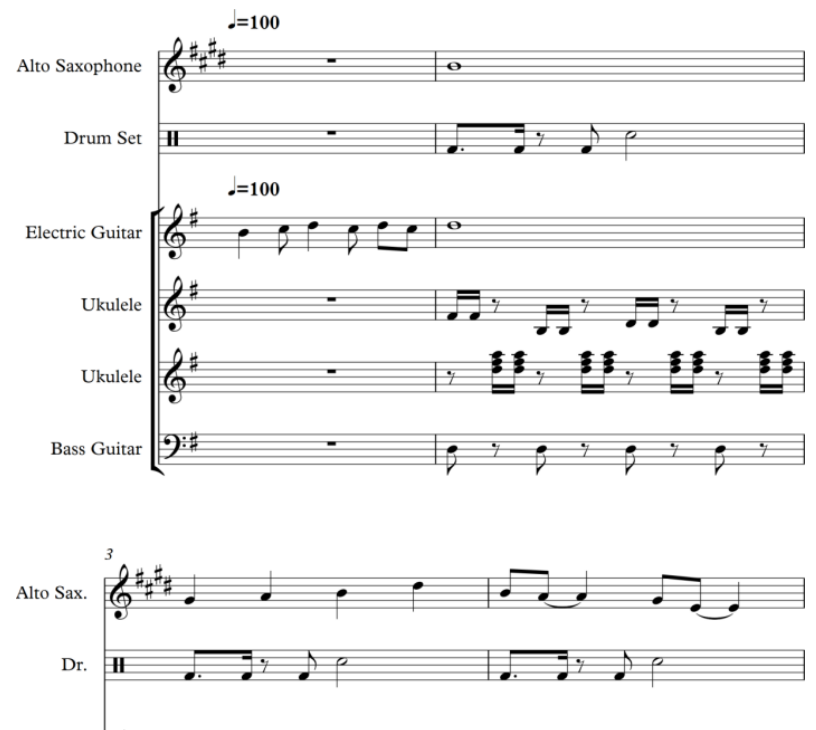

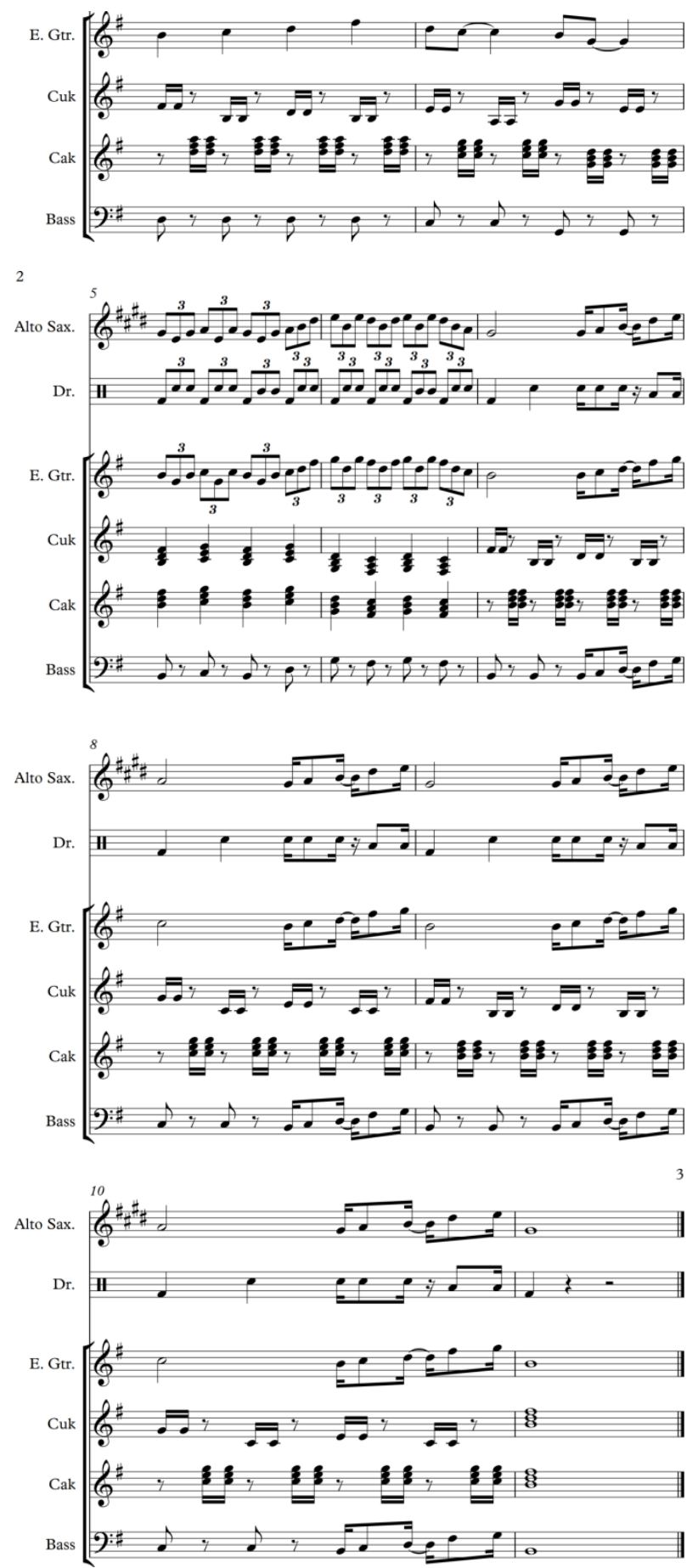

Notasi 2: Musik Srepeg Sar Kliwon karya Congwayndut. (Transkrip notasi: Aji Agustian dan Eko Aprianto)

\section{Ceritera}

Dilihat dari ide ceritera sebenarnya Congwayndut masih berpijak dari pakem pengambilan sumbernya dari dua epos yakni Ramayana dan Mahabarata. Namun demikian, jika kita menilik pada kedua sumber tersebut dan dikaitkan dengan pakem pedalangan baik di

gaya Surakarta maupun Yogyakarta, akan lekat dengan hal itu. Hal yang demikian tersebut justru akan membuat para penikmat menganggap seni pedalangan menjadi bentuk tontonan yang sangat berat dan butuh teknik interpretasi tinggi untuk dapat memahami nilai, dan bahkan hanya sekedar untuk mengetahui ceriteranya. Dengan berdasarkan hal tersebut, Congwayndut berupaya untuk membuat terobosan dalam rangka agar wayang dapat dekat dengan generasi muda, yang nantinya akan merawat, mengelola, dan mengembangkan seni pedalangan itu sendiri.

Ide yang dimunculkan oleh Congwayndut dalam pertunjukan wayang untuk inovasi ceritera lebih mengangkat fenomena kehidupan di lingkungan masyarakat terkini. Fenomena tersebut meliputi kondisi sosial, politik, ekonomi, sampai dalam aspek kehidupan yang sifatnya pribadi seperti percintaan (Romadona, 2019a: 44). Tematema terkait dengan fenomena kehidupan tersebut dituangkan dengan personifikasi tokoh wayang dari epos ceritera Ramayana dan Mahabarata. Kemasan ceriteranya dibawakan dengan suasana yang ringan, lucu, dan menarik, sehingga masyarakat dan penonton di samping mendapatkan edukasi lewat pengalaman melihat pertunjukan juga esensi hiburan sangat tampak.

Konsep pembauran dalam ceritera adalah menggabungkan tema-tema ceritera berbasis fenomena terkini dengan epos ceritera yang menjadi pakem dalam seni pedalangan. Kemasan dagelan yang dihadirkan menjadi konsep utama dalam gagasan ceritera Congwayndut. Karena itulah desain ceriteranya selalu dibuat ndagel dengan tujuan untuk menghibur penonton dan masyarakat yang menyaksikan sajian pertunjukannya. Namun demikian, meskipun konsep sajian ceritera dikemas dengan ndagel, Congwayndut tetap memegang prinsip bahwa ceritera yang disampaikan harus mulih. Mulih yang dimaksudkan di sini adalah selesai atau sampai pada ending dari ceritera yang disampaikan.

\section{Pertunjukan}

Aspek pembauran ketiga yang dihadirkan oleh Congwayndut sebagai sebuah bentuk terobosan 
baru dalam sajian pergelarannya adalah aspek bentuk pertunjukannya. Sebagaimana disampaikan pada pembahasan di awal, bahwa Congwayndut menggunakan strategi pertunjukan teater dalam menyampaikan alur atau bentuk pertunjukan ini. Oleh karena itu, kemasan pertunjukan wayang yang disajikan tidak seperti pertunjukan wayang kulit pada umumnya, namun lebih menyerupai pertunjukan teater. Dalam mempergelarkan pertunjukannya, Congwayndut mencoba untuk menawarkan pembauran genre seni pertunjukan yang dikemas dalam satu sajian, yakni: (1) Meniadakan tata urutan babak berdasarkan sistem pathet; (2) Menghadirkan gerak sebagai bentuk koreografi dalam pertunjukan wayang; dan (3) Bahasa yang bersifat interaktif dan komunikatif dengan penonton.

\section{Peniadaan Tata Urutan Babak Berdasarkan Pathet}

Konsep pembabakan dalam pergelaran Congwayndut sebagaimana telah disinggung dalam pembahasan sebelumnya, menawarkan sesuatu yang berbeda dengan pertunjukan wayang sebagaimana lazim disaksikan. Dalam pertunjukan wayang kulit purwa, menggunakan pembabakan dengan sistem pathet, yakni pathet nem, sanga, dan manyura. Tidak demikian dengan pertunjukan Congwayndut. Adegan atau babak yang ada dalam Congwayndut, lebih dekat dengan pembabakan dalam alur pertunjukan teater, yakni diawali dengan pengenalan masalah, munculnya konflik, klimaks, penyelesaian konflik, dan penutup.

Congwayndut mengakomodasi dan menerapkan pendekatan pembabakan berdasarkan alur pertunjukan teater. Hal ini bukan bermaksud ingin meninggalkan tradisi pedalangan yang disebut pathet. Karena pada dasarnya, dengan menggunakan musik keroncong sebagai latar ilustrasi musikal pertunjukan akan lebih luwes dalam mengembangkan persoalan dalam ceritera. Artinya, Congwayndut tidak berusaha untuk membelenggu diri dengan sistem pembabakan yang ketat seperti pada pertunjukan pewayangan pada umumnya. Namun, dalam setiap pertunjukannya, Congwayndut selalu disiplin untuk menyelesaikan alurnya. Dengan kata lain, dalam setiap lakon ceritera yang disampaikan selalu selesai dengan alur yang sudah ditetapkan.

\section{Menghadirkan Elemen Gerak sebagai Bentuk Koreografi}

Elemen gerak yang dihadirkan dalam pertunjukan Congwayndut, bukan semata-mata gerak boneka wayang yang dimainkan oleh dalang. Namun elemen gerak yang disajikan oleh para penyanyi, dalang, dan bahkan seringkali dalam pertunjukan, Congwayndut menghadirkan penari untuk memperkuat suasana adegan. Para penyanyi menampilkan koreografi gerak, meskipun secara sederhana namun tampak. Misalnya ketika menyanyikan lagu untuk ilustrasi sedih, para penyanyi juga menampilkan gerak yang menggambarkan suasana sedih tersebut. Koreografi berbasis hip-hop disajikan oleh dalang pada saat membuka pertunjukan. Dalang menyampaikan kepada audiens atau penonton mengenai lakon yang akan dibawakan dalam pertunjukan dengan model penyanyi hip-hop, tentu saja ekspresi dalang juga dimunculkan melalui elemen gerak tertentu sebagaimana penyanyi hip-hop.

Selain itu, Congwayndut juga pernah menampilkan penari sebagai representasi salah satu tokoh wayang yang hadir dalam pertunjukannya. Seperti pada lakon Karmapala, Congwayndut menghadirkan tokoh Duryudana dari pemain teater, dan tokoh Sengkuni dari penari. Dalam pertunjukan ini, Sengkuni yang diperankan oleh seorang penari sekaligus berperan sebagai koreografer dalam sajian pertunjukan tersebut, menampilkan gerak koreografi yang tidak lazim dilakukan oleh tokoh Sengkuni, yakni melakukan kiprah dan solah. Padahal dalam khazanah pewayangan, tokoh Sengkuni memang digambarkan sebagai sosok yang secara fisik sangat terbatas, tidak pernah melakukan solah apalagi kiprah. Menurut koreografer dalam lakon Karmapala yakni Anggono Kusumo Wibowo, dalam konsep pertunjukan Congwayndut, memang ada keleluasaan yang diberikan kepada koreografer untuk menghadirkan sesuatu yang menarik dalam pertunjukan, karena itu dihadirkanlah kiprah yang dilakukan oleh tokoh Sengkuni, ketika ditunjuk 
sebagai senapati atau panglima perang terakhir dari Kurawa dalam perang Bharatayuda.

\section{Bahasa yang Interaktif dan Komunikatif}

Segmentasi penonton dan penikmat Congwayndut adalah generasi muda yang hidup di era milenial. Meskipun tidak jarang, ada penonton dan penikmat yang berasal dari kalangan penggemar wayang kulit yang dapat dikategorikan sepuh. Oleh karenanya, aspek bahasa yang digunakan lebih bersifat interaktif dan komunikatif, untuk semua kalangan penonton. Hal ini sejalan dengan konsep pertunjukan Congwayndut yang ingin menyampaikan pesan dan nilai secara langsung kepada para penonton. Merujuk pada sifatnya, maka bahasa yang digunakan juga menggunakan konsep pembauran, artinya berbagai varian bahasa disajikan dalam pertunjukan ini yakni bahasa Jawa krama alus dan ngoko, bahasa Indonesia, dan bahasa keseharian yang digunakan oleh masyarakat. Hal ini ditujukan untuk menjalin kedekatan dengan para penonton dan penikmat wayang dengan dalang dan pertunjukannya. Tidak jarang, diselipkan dialog antara dalang dan salah seorang penonton yang hadir di saat pertunjukan. Dialog yang disampaikan ini, biasanya masih mengupas perjalanan ceritera yang disampaikan, namun diaktualisasikan dengan kondisi terkini dalam kehidupan nyata. Hal tersebut, memancing penonton lain juga menimpali dengan celotehancelotehan yang disampaikan langsung kepada dalang dalam pertunjukan tersebut. Konsep dialog semacam ini memiliki tujuan agar inti ceritera menjadi mudah diterima dan dipahami oleh para penonton. Apalagi ini diperkuat dengan konsep panggung yang tidak membatasi antara penyaji dengan penonton, yang memang dibiarkan berbaur dalam satu panggung yang digelar.

Narasi baku dalam pertunjukan wayang kulit purwa, tidak begitu saja ditinggalkan, kendati tidak menjadi dominan. Artinya, pertunjukan Congwayndut masih menjaga akar pakem pedalangan dalam penggunaan yang tidak dominan. Dengan demikian, upaya membahasakan yang lebih sederhana ala Congwayndut ini masih berpegang pada tradisi pewayangan yang berlaku di Jawa.

\section{Kesimpulan}

Terobosan inovasi yang dilakukan oleh Congwayndut sebagai salah satu kelompok seni pertunjukan di Surakarta, lebih bertujuan pada menjawab sebuah tantangan atas mulai tersisihnya pertunjukan wayang kulit sebagai dampak dari era industri digital. Pembauran genre menjadi kata kunci dalam inovasi pertunjukan yang dikemas oleh Congwayndut secara interaktif. Tujuannya adalah menyederhanakan proses penyampaian pesan dan nilai dalam pewayangan kepada generasi muda berbasis budaya milenial ini, dengan tidak menghilangkan esensi tradisi pewayangan yang berlaku.

Bentuk pembauran genre yang menjadi konsep inovasi pertunjukan Congwayndut terimplementasi dalam aspek musik yang membaurkan keroncong sebagai pilar musikal pertunjukannya dengan genre musik kontemporer dan dikemas dalam format combo band, ceritera, dan bentuk pertunjukan yang disajikan. Dengan menghadirkan pembauran genre ini, ternyata mampu menarik minat generasi muda untuk kembali mendekat dan menerima pesan serta nilai yang disampaikan melalui kemasan pertunjukan Congwayndut. Namun demikian, konsep pembauran genre sebagai wahana inovasi ini tetap memperhatikan akar tradisi baku pewayangan. Artinya, Congwayndut hadir sebagai gridder seni pertunjukan wayang kulit yang telah berakar kuat dalam tradisi budaya Jawa.

\section{Kepustakaan}

A'yun, Wildan Qurrata, and Abdul Rachman. 2019. "Keroncong in Jamaican Sound, Sebuah Inovasi Dalam Melestarikan Musik Keroncong di Bandung." Jurnal Seni Musik 8(1):34-42. doi: https://doi.org/10.15294/ jsm.v8i1.30935.

Christy, Dian Eka, Wasino Wasino, and Andi Suryadi. 2019. "Musik Keroncong di Surakarta: Perjalanan dari Tahun 1960 hingga 1995.” Indonesian Journal of Coservation 8(1):1-10. doi: https://doi.org/10.15294/ijc.v8i1.22677.

Czikszentmihali, Mihaly. 1999. "Implication of a Systems Perspective for The Study of 
Creativity." in Handbook of Creativity, edited by R. J. Sternberg. New York: Cambridge University Press.

Harpawati, Tatik, Lono L. Simatupang, Timbul Haryono, and Sri Hastanto. 2015. “Keselarasan Lagu Dengan Fungsi Pocapan Dalam Pertunjukan Wayang Lakon Sudhamala." Resital: Jurnal Seni Pertunjukan 16(3):153-65. doi: https://doi.org/10.24821/ resital.v16i3.1680.

Kiswanto, Kiswanto, Rr. Paramitha Dyah Fitriasari, and Timbul Haryono. 2019. ""Transformasi Multipel dalam Pengembangan Seni Kuda Kepang.” Dance \& Theatere Review: Jurnal Tari, Teater, Dan Wayang 2(1):1-16. doi: https://doi.org/10.24821/dtr.v2i1.3295.

Marajaya, Made, and Dru Hendro. 2021. “Makna Ruwatan Wayang Cupak Dalang I Wayan Suaji."” Mudra, Jurnal Seni Budaya 36(1):6374. doi: https://doi.org/10.31091/mudra. v36i1.

Mudra, I. Wayan, Mercu Mahadi, and Ni Kadek Karuni. 2020. “Inovasi Produk Kriya Di Bali.” Gorga, Jurnal Seni Rupa 9(1):56-63. doi: https://doi.org/10.24114/gr.v9i1.17796.

Mulyani, Ai, and Riyana Rosilawati. 2020. "Kreativitas Rd. Tjetje Somantri dalam Tari Puja." Panggung, Jurnal Seni Budaya 30(1):7086. doi: http://dx.doi.org/10.26742/ panggung.v30i1.1144.

Prakasih, Putu Paristha, I. Gede Yudarta, and Hendra Santosa. 2018. "Tirtha Campuhan: Karya Komposisi Baru dengan Media Gamelan Semar Pagulingan.” Resital: Jurnal Seni Pertunjukan 19(3):113-21. doi: https:// doi.org/10.24821/resital.v19i3.2452.

Rachmawati, Putri, and Nanik Sri Prihatini. 2019. "Inovasi Dolalak Lentera Jawa II Karya Melania Sinaring Putri." Panggung, Jurnal Seni Budaya 29(4):314-27. doi: http://dx.doi. org/10.26742/panggung.v29i4.1047.

Ridwan, Ridwan, Tatik Narawati, Uus Karwati, and Yudi Sukmayadi. 2020. "Creativity and Innovation of Artist in Maintaining and Developing the Songah Tradition." Harmonia, Journal of Arts Research and Education
20(2):213-22. doi: https://doi.org/10.15294/ harmonia.v20i2.25169.

Romadona, Eko Aprianto. 2019a. "Penciptaan Musik Keroncong dan Wayang Inovatif Dalam Pertunjukan Congwayndut." Sorai: Jurnal Pengkajian Dan Penciptaan Musik 12(1):12-20. doi: https://doi.org/10.33153/ sorai.v12i1.2619.

Romadona, Eko Aprianto. 2019b. "Penciptaan Musik Keroncong dan Wayang Inovatif Dalam Pertunjukan Congwayndut." Institut Seni Indonesia Surakarta.

Saaduddin, Saaduddin, and Sherli Novalinda. 2017. “Pertunjukan Teater Eksperimental Huhh Hahh Hihh: Sebuah Kolaborasi Teater Tari." Ekspresi Seni, Jurnal Ilmu Pengetahuan Dan Karya Seni 19(1):39-57. doi: http:// dx.doi.org/10.26887/ekse.v19i1.128.

Salim, Muhammad Nur. 2020. "Kreativitas Rahayu Supanggah pada Film Opera Jawa Karya Garin Nugroho." Acintya, Jurnal Penelitian Seni Budaya 12(2):158-69. doi: https://doi. org/10.33153/acy.v12i2.3580.

Sudirga, I. Komang. 2020. "Innovation and Change in Approaches to Balinese Gamelan Composition." Malayan Journal of Music 9(1):42-54. doi: https://doi.org/10.37134/ mjm.vol9.4.2020.

Sukistono, Dewanto. 2014. "Pengaruh Karawitan Terhadap Totalitas Ekspresi Dalang dalam Pertunjukan Wayang Golek Menak Yogyakarta." Resital: Jurnal Seni Pertunjukan 15(2):179-89. doi: https://doi.org/10.24821/ resital.v15i2.852.

Wrahatnala, Bondet. 2018. Sosiologi Musik. 1st ed. Surakarta: ISI Press.

Wrahatnala, Bondet. 2020. "Congwayndut: Refleksi Fungsionalisme Struktural Seni Pertunjukan Yang Melintas Batas." Acintya, Jurnal Penelitian Seni Budaya 12(2):116-23. doi: 10.33153/acy.v12i2.3576.

Yuliza, Fresti. 2020. "Creativity of Art in Sendratari Ramayana as An Example Transformation Process." Ekspresi Seni, Jurnal Ilmu Pengetahuan dan Karya Seni 22(2):83-92. doi: http:// dx.doi.org/10.26887/ekspresi.v22i2.1013. 